\title{
PELANGGARAN WAYANG TERHADAP AGAMA DAN SOLUSINYA
}

\author{
Oleh Muh. Mukti \\ Dosen Jurusan Pendidikan Seni Tari \\ Fakultas Bahasa dan Seni UNY
}

\begin{abstract}
Abstrak
Wayang dalam perspektif agama Islam selama ini selalu dipandang positif oleh masyarakat umum bisa mengantarkan mamusia sampai pada Penciptanya, tetapi tidak demikian oleh orang alim, wayang dianggap sebagai pelanggaran terhadap agama Islam karena tidak bisa mengantarkan manusia sampai pada Penciptanya, hingga harus diberi solusinya.

Tulisan ini bertujuan untuk menyampaikan pelanggaran wayang terhadap agama Islam, serta solusinya agar bisa mengantarkan manusia sampai pada Penciptranya.

Pelanggaran wayang terhadap agama Islam, pertama wayang bukanlah dakwah, kedua bukan taklim, ketiga bukan ibadah, hingga tidak bisa mengantarkan manusia sampai pada Penciptanya, Adapun Solusinya, wayang harus disambungkan dengan dakwah khuruj fii sabiilillaah.tiga hari, empatpuluh hari, atau empat bulan.
\end{abstract}

\section{Kata Kunci: Wayang, pelanggaran, dakwah}

The Infractions of Wayang to Religion and the Solutions to the Problem

\begin{abstract}
All this time wayang in Islamic perspective is always viewed by the society as a positive means that could lead humans to their Creator, However, religious people do not think the same way as they see wayang as a kind of infractions of Islam since it could not lead humans to God, and thus there should be some solutions for it.

The purpose of this paper is to reveal wayang's infractions of Islam and the solutions so that wayang could lead humans to God.

Wayang's infractions of Islam appear in the form of the facts that, first, wayang is not a religious proselytizing; second, it is not a ta'lim; and, third, it is not a pray. Thus, it cannot guide humans to God. The solution for this is wayang should be connected to religious khuruj fii sabiilillaah proselytizing in three days, forty days, or four months.
\end{abstract}

\section{Keyword: wayang, infraction, proselytizing}




\section{A. Pendahuluan}

Wayang selama ini, dalam perspektif Islam, selalu dipandang positif oleh masyarakat umum. Hal ini disebabkan sejak awal wayang digunakan untuk kepentingan dakwah oleh para wali. Dakwah dengan media wayang telah menjadikan banyak orang masuk Islam. Wayang menjadikan pesan-pesan Islam lebih mudah diterima masyarakat sehingga Islam menjadi agama yang dianut mayoritas masyarakat Indonesia.

Amijoyo (Hazim, 1991:15) mengatakan bahwa wayang merupakan gambaran dari sebuah alam yang sempurna. Dalang diibaratkan sebagai "tuhan", wayang diibaratkan sebagai manusia, dan kotak tepat menyimpan wayang merupakan asal manusia tiada. Dalang yang sebagai "tuhan" mempunyai purbawasesa untuk menentukan nasib hidup matinya wayang. Wayang, dengan demikian, jika dihayati benar akan menjadikan orang semakin tebal imannya

Kasidi (1991:100) mengatakan bahwa suluk yang dilantunkan oleh dalang dalam wayang itu asalnya dari kata salaka, artinya jalan, yaitu jalan yang ditempuh. Suluk merupakan doa yang jika dihayati benar akan dapat mengantarkan dalang sampai pada manunggaling kawula-Gusti atau makrifat kepada Allah.

Sementara itu, Effendi (1977: 80) mengatakan bahwa lakon Dewaruci adalah cerita makrifat. Oleh karena itu, jika dihayati benar, akan menjadikan orang paham terhadap penciptanya, yakni Tuhan. Wayang telah berhasil mengantarkan Islam menjadi agama mayoritas. Lebih lanjut Effendi (1977:7) mengatakan bahwa maksud perabot-perabot wayang seperti kendang yang berbunyi, "tak ndang tak ndang” itu artinya bersegeralah. Saron yang berbunyi, "nang ning nung nong" artinya di sana. "Di sana" yang dimaksud adalah bahwa dalam agama Islam ada kebesaran Tuhan. Bunyi tersebut sekaligus juga bermakna ajakan, "Bersegeralah untuk masuk atau memeluk agama Islam, maka anda akan melihat kebesaran Tuhan di sana (di dalam agama Islam).”

Solihin (2009:17) mengatakan bahwa wayang merupakan penggambaran dari sebuah makrokosmos dan mikrokosmos. Oleh karena itu, jika dihayati benar akan bisa memberikan kontribusi terhadap perbaikan budaya Jawa yang kental dengan suasana agama—sangkan paran.

Sebuah pertanyaan patut diajukan, mengapa wayang selalu dipandang positif oleh masyarakat dan nyaris tidak ada yang berani berpendapat miring? Terhadap pertanyaan itu Abdullah (Sahana, 2009: 5) memberikan jawaban. Pertama, karena wayang telah berhasil meninabobokkan masyarakat dengan berbagai perhidmatan-nya, seperti sabet yang akrobatik, 
penataan sindhen yang artistik sehingga bisa dilihat langsung oleh dalang dan penonton. Kedua, sejak awal wayang telah dipandang positif, terutama setelah datangnya Islam dan digunakannya sebagai media dakwah para Wali.

Jawaban tersebut menyiratkan tidak demikian sesungguhnya wayang. Artinya dalam perspektif agama Islam layak untuk dikaji kembali, karena ternyata selain mereka yang sepakat, ada juga sebagian kalangan Umat Islam yang menganggap pertunjukan wayang sebagai pelanggaran. Oleh karena itu, tulisan ini mendasarkan pada pertanyaan bagaimana pelanggaran wayang dalam pandangan Islam, serta bagaimana pula kemudian solusinya?

\section{B. Pengertian}

\section{Agama}

Agama adalah manifestasi Tuhan berisi perintah dan larangan untuk mengantarkan manusia agar kenal pada Penciptanya, yakni Allah dzat yang khaliq artinya yang menciptakan, malik yang merajai, dan raziq yang memberi rizki (Zakariyya, 2000:5). Adapun untuk mengantarkan manusia sampai pada Penciptanya itu dalam agama Islam sesungguhnya telah ditetapkan ada tiga, yaitu dakwah, taklim, dan ibadah. Hal ini seperti disebutkan dalam AQur'an , "Ya Allah, bangkitkan dari kalangan mereka seorang Rasul yang menyampaikan ayatayat kebesaranmu (dakwah) mengajarkan kitab (taklim), dan membersihkan hati (ibadah)." (Q.s. Al-Baqarah: 129).

Dakwah artinya mengajak, yaitu mengajak manusia untuk taat kepada Allah dengan bijaksana atau hikmah sesuai dengan maqam atau kekuatan sasaran manusia yang diajak. Hal ini seperti disampaikan Qur'an surat An-Nahl 125, “Ajaklah manusia kepada Tuhanmu dengan cara bijaksana." (Abdullah (2002:3). Dakwah karena pengertiannya mengajak manusia agar taat kepada Allah dengan cara bijaksana, maka ia bergerak dari segala sesuatu yang dilarang oleh Allah kepada segala hal yang diperintahkan Allah, hingga seperti menerima pelanggaran, tetapi sebenarnya tidak. Kalau menerima pelanggaran, itu hanya ikram atau dalam istilah Jawa nggutuk lor ngarah kidul, ngono ning ora ngono,ngeli ning ora keli (pura-pura).

Taklim atau lengkapnya taklim wal taklum, artinya belajar-mengajar agama Islam. Taklim karena artinya belajar-mengajar agama Islam, maka seluruh ilmunya harus datang dari Al-Qur'an dan Al-Hadits dan tidak boleh dari yang lain. (Zakariyya, 2000). 
Ibadah artinya mengabdi, yaitu mengabdi kepada Allah. Mengabdi kepada Allah artinya mengamalkan ajaran agama Islam secara benar (Zakariyya, 2000). Berbeda dengan dakwah yang sifatnya bergerak antara pelanggaran dan kebenaran, ibadah ini sifatnya mandeg dalam kebenaran saja.

Aplikasi terhadap agama taklim dan ibadah di kalangan umat Islam relatif sama, kecuali dakwah. Aplikasi agama untuk taklim adalah mencari ilmu dengan cara berguru kepada alim ulama, untuk ibadah menjalankan syariat dengan benar, seperti shalat, zakat, dan puasa. Adapun aplikasi khusus untuk jamaah Tabligh adalah keluar dakwah khuruj fii sabiilillah tiga hari, empat puluh hari, atau empat bulan, sekaligus ini menjadi solusi terhadap pelanggaran agama yang ada baik dakwah, taklim maupun ibadah.

\section{Wayang}

Wayang adalah sebuah seni drama yang dipertunjukkan. Pengertian wayang tersebut menyiratkan adanya cerita, pelaku, perabot, dan operasional pertunjukan yang selanjutnya diterangkan kemudian.

Cerita wayang adalah Mahabarata dan Ramayana, keduanya merupakan hasil karya sastra untuk kepentingan agama Hindu. Mahabarata menceritakan peperangan Pandawa-Kurawa karena rebutan harta dan tahta Hastina, sedang Ramayana menceritakan peperangan Rama-Rahwana karena rebutan wanita Dewi Sinta (Sudarsono, 1996:7).

Pelaku wayang paling utama adalah dalang, didukung oleh pengrawit atau penabuh gamelan yang biasa disebut dengan istilah niyaga, wirasuwara atau penyanyi laki-laki atau biasa disebut dengan istilah penggerong, dan suwarawati atau penyanyi perempuan atau biasa disebut dengan istilah pesindhen, dan penonton.

Perabot wayang paling utama adalah wayang.Wayang ini bentuknya pipih seperti patung atau gambar manusia bernyawa, didukung dengan alat musik bernada yakni gamelan seperti kendang, gong-kempul, balungan saron, demung, centhe, seruling, kenong, siter, dan rebab. Perabot wayang selain disebutkan juga ada gawang-kelir sebagai alas permainan wayang, bentuknya kain terbentang di atas kayu dengan asesori patung ular naga beradu pethit.

Operasional penyajiannya, cerita wayang Mahabarata dan Ramayana dipertunjukkan dengan ada judul, tokoh, dan alur cerita. Judulnya bisa macam-macam, seperti Wirataparwa dan Dewaruci. Kalau judulmya Wirataparwa, maka tokohnya adalah Pandawa-Kurawa, sedang alur 
ceritanya mulai dari adegan Wirataprabu Matswapati susah kehilangan cucunya Pandawa sampai dengan adegan bahagia bisa bertemu kembali dan tanceb kayon (selesai).

Pelaku dalang, pengrawit, wiraswara, mengenakan baju kejawen, seperti blangkon, buskab, jarit, keris, dan stagen. Swarawatinya tabarruj atau memakai celak, benges, mengenakan baju kebaya, dan sampir selendang panjang. Pelaku duduk ihtilat campur antara laki-laki dan perempuan sesuai dengan penataan perabot yang ada, dalang paling depan menghadap kelir, sindhen di sebelah kanan, menghadap dalang dan atau penonton, pengrawit dalam hal ini penggender di belakang dalang berikut penggendang, pengerong di sebelah kiri, pembonang di sebelah kanan, pembalung di belakang pengendang, dan berikut penonton ada di belakang pengrawit menghadap wayang. Pelaku sesuai dengan perannya, dalang terlebih dulu doa japa mantra, kemudian memainkan wayang dengan sebentar-sebentar suluk mengucapkan ong atau hong, pengrawit menabuh gamelan, penggerong, dan pesinden menyanyikan lagu, penonton menikmati sambil sebentar-sebentar tertawa dan tepuk tangan.

Wayang memakan waktu semalam suntuk atau tidak kurang dari tujuh jam mulai dari Jam 21.00 sampai dengan adegan tanceb kayon jam 04.00 pagi, bahkan menurut pakem (tuntunan untuk mendalang) sampai dengan jam 06.00. pagi (Suratno, 1964). Wayang untuk sekali pentas, lazimnya memakan biaya tidak sedikit, hingga karena seluruh operasional penyajiannya selalu dinilai dengan rupiah, maka dalang-dalang yang sudah popular, seperti Anom Suroto, Manteb Sudarsono, dan Enthus Susmono, berani mematok harga tidak kurang dari Rp 30.000.000. (tigapuluh juta Rupiah) (Murtiyoso, 1996:20).

\section{Pelanggaran Wayang terhadap Agama}

Pelanggaran wayang terhadap agama Islam selama ini, wayang bukanlah dakwah, bukan taklim, dan bukan pula ibadah, hingga tidak mengantarkan manusia sampai pada Penciptanya. Wayang yang bukan dakwah, bukan taklim, dan bukan ibadah yang tidak bisa mengantarkan manusia sampai pada Penciptanya ini bisa dilihat berdasar pengertian agama seperti telah disampaikan.

Wayang bukan dakwah, karena wayang tersebut mandeg dalam wayang itu sendiri, dan tidak bergerak pada usaha dakwah yang sebenarnya, yakni khuruj fii sabiilillaah tiga hari, empat puluh hari, atau empat bulan. Wayang bukan dakwah tersebut karena memang pertunjukan tersebut sebuah terminologi tunggal, artinya setelah adegan tanceb kayon kemudian selesai, 
setelah selesai sudah, tidak terhubung ke mana-mana. Dalam istilah Jawa barji barbeh salaman Petruk,bubar siji bubar kabeh ratau pethuk: selesai satu selesai semua tidak pernah ketemu lagi, hingga sebuah pertanyaan layak disampaikan "sekiranya wayang itu bergerak kepada dakwah, bergerak kepada dakwah yang seperti apa ?".

Wayang bukan taklim, karena ilmunya bukan datang dari Al-Qur'an dan Al-Hadits, tetapi datang dari agama lain, seperti Hindu dan Budha. Hal ini bisa dilihat seperti cerita datang dari kitab Ramayana dan Mahabarata agama Hindu. Demikian pula tokohnya ada para dewa seperti dewa Wisnu, dewa Brahma, dewa Yama, dan sebagainya, juga yang lain Pandawa dan Kurawa. Perabot wayangnya pipih seperti patung atau gambar manusia bernyawa, tidak ada suasana agama yang laki-laki memakai anting-anting, gelang, tangan gelang kaki, kalung, pelakunya duduk ihtilat maksudnya campur antara laki-laki dan perempuan, pesindennya bersolek, gamelannya alat musik bernada, dan masih banyak lagi yang tidak disampaikan di sini.

Wayang bukan ibadah, karena sebagai ibadah bertentangan dengan syariat. Wayang sebagai ibadah bertentangan dengan syariat tersebut bisa dilihat misalnya dalang ketika melantunkan bahasa Ong atauHong. Ong atau Hong adalah bahasa persembahan kaum Hindu. Ong atau Hong karena bahasa persembahan kaum Hindu, maka ketika dalang melantunkan Ong atau Hong itu berarti tasabuh atau meniru-niru suatu kaum dalam hal ini adalah Hindu, sedang tasabuh atau meniru-niru suatu kaum dalam agama Islam sangat dilarang atau bertentangan dengan syariat, dasarnya adalah: mantasabbaha biqaumin fahuwa minhu: barang siapa yang meniru-niru suatu kaum, maka digolongkan menjadi kaum itu (Hadits sahih). Wayangnya seperti patung atau gambar manusia bernyawa, dan gawang kelirnya ada asesori patung ular juga bertentangan dengan syariat, dasarnya: "orang yang membuat patung atau gambar makhluk bernyawa, kelak harus memberinya ruh, pada hal mereka tidak mampu" (Hadits sahih). Duduk ihtilat atau campur baur antara laki-laki dan perempuan dengan bisa saling bicara dan memandang juga dilarang, dasarnya adalah walaa taqrabuzzina: dan jauhilah olehmu dari perbuatan zina (Hadits sahih).

Wayang oleh karena demikian bukan dakwah, bukantaklim, dan bukan pula ibadah seperti telah disampaikan, maka sudah barang tentu tidak bisa mengantarkan manusia sampai pada Penciptanya, tetapi pada yang lain, seperti harta, tahta, atau wanita sebagai pokok-pokok selain daripada Pencipta yang paling dikenal oleh masyarakat selama ini. 
Wayang dengan realitas tanggapan yang ada seperti dipatok dengan harga tiga puluh atau empat puluh juta rupiah atau berapa pun oleh dalang-dalang sekarang ini seperti Anom Suroto, Manteb Sudarsono, dan Enthus Susmono, cukuplah dikatakan sampai pada harta.

Wayang dengan diberinya kewenangan penuh kepada dalang sebagai pemimpin yang menentukan berbagai hal seperti membagi uang tanggapan, menentukan jadwal latihan, menentukan waktu keberangkatan menuju tempat pertunjukan-pagi, siang, sore, malam, dan sebagainya (lihat Van Gronendael, 1985:78), cukuplah dikatakan sampai pada harta.

Wayang dengan ditatanya posisi pesindhen menghadap dalang dan penonton hingga sesekali bisa dipandang, bisa diajak bicara, bahkan memang sengaja demikianmalah sebagai hiburan (Soetarno, 1978), cukuplah dikatakan sampai pada wanita.

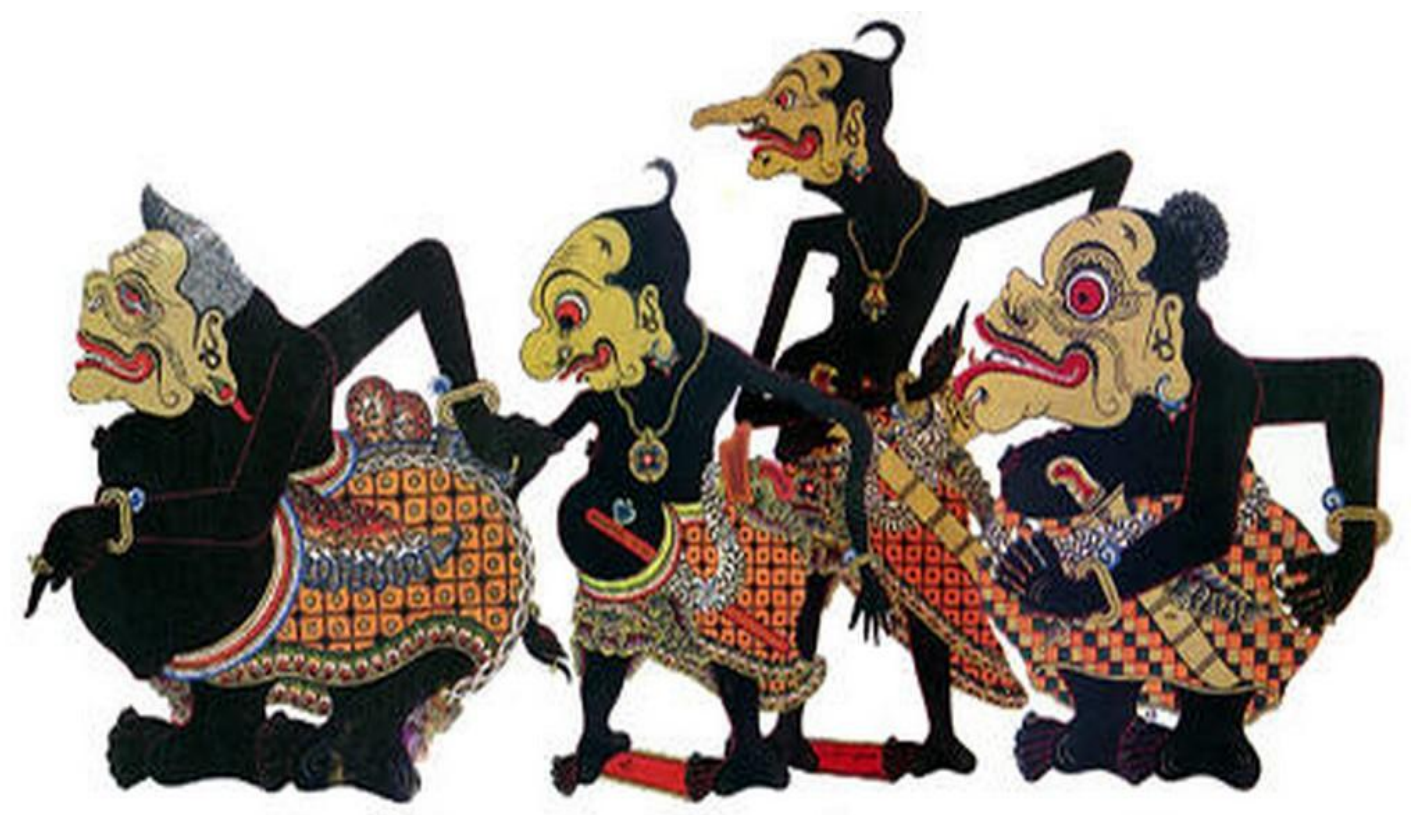

Gambar 1. Di antara pelanggaran wayang terhadap agama Islam, Panakawan seperti gambar manusia bernyawa, laki-laki, tetapi memakai anting-anting, gelang, dan kalung

\section{Solusi Pelanggaran Wayang terhadap Agama Islam}

Solusi pelanggaran wayang terhadap agama Islam agar bisa mengantarkan manusia sampai pada Penciptanya, wayang tersebut haruslah disambungkan dengan dakwah khuruj fii sabilillaah keluar tiga hari, empatpuluh hari, atau empat bulan. Adapun caranya, wayang dengan segala unsurnya dibuat ada suasana agama sedemikian rupa baik cerita, pelaku perabot, dan operasioal pertunjukannya. 
Ceritanya tetap Mahabarata dan Ramayana yang ada, tetapi dibuat Islami baik judul, tokoh dan alur ceritanya. Judul Bimasuci, dibuat menjadi Bima Dakwah, tokohnya Pendeta Durna, dibuat menjadi tokoh Kyai Haji Durna, Gareng Petruk dibuat menjadi Abdulah Sugareng dan Muhammad Supetruk. Alur ceritanya mulai dari Bratasena berguru makrifat kepada Kyai Haji Durna, sampai dengan keberhasilannya ketemu Dewaruci-paham agama.

Pelaku dalang, pengrawit, wiraswara, mengenakan baju Islami, seperti serban, jubah atau baju koko lengan panjang, celana blunci tidak panjang bawah kemiri, tidak pendek atas dhengkul. Pelaku ditata sedemikian rupa sesuai dengan penataan perabot; dalang paling depan, pengrawit dalam hal ini penggendher di belakang dalang, berikut pengendang, pengegong di sebelah kiri, pembonang di sebelah kanan, pembalung di belakang pengendang, dan berikut penonton ada di belakang pengrawit. Penting untuk diperhatikan agar pelaku ini dalang dan pengrawit duduk di atas trap, penonton lesehan duduk iftiras sepertia duduknya orang shalat dalam tahiyat awal di lantai bawah.

Pelaku sesuai dengan perannya, dalang terlebih dulu ada wudlu doa secara sunnah bismillaahirrahmaanirrahiim kemudian memainkan wayang dengan sebentar-sebentar suluk mengucapkan shalawat "allaahumma shalli 'alaa Muhammad", pengrawit menabuh gamelan, rebana dan bedhug, penggerong melantunkan lagu, dan penonton tawajuh menikmati wayang, jika terkesan mengucapkan subhaanallaah.

Wayang memakan waktu dua jam mulai talu bakda Isya jam 20.00 sampai dengan 22.00 menjelang malam, atau tujuh jam mulai jam 20.00. sore sampai dengan jam 03.00 menjelang pagi atau Subuh. Setelah wayang usai, disambungkan dengan dakwah, caranya dalang kemudian tasykil atau mengajak langsung kepada penonton untuk dakwah khuruj fii sabilillah tiga hari, empat puluh hari atau empat bulan mengikuti kemampuan yang ada. Asumsinya karena penonton sudah mengetahui tentang pentingnya agama, maka penonton kemudian dakwah khuruj fii sabiilillah keluar tiga hari, empat puluh hari, atau empat bulan, dengan terlebih dulu diberi bayan hidayah atau pembekalan berisi tentang cara dakwah. Selesai dakwah, kemudian diberi bayan tangguh atau pesan-pesan untuk tetap dakwah kepada diri, ahli keluarga, dan masyarakatnya. Dengan keluarnya penonton dakwah khuruj fii sabilillah tiga hari, empatpuluh hari atau empat bulan demikian, maka berarti sambunglah wayang ini dengan dakwah khuruj fii sabiilillaah hingga penonton kemudian kenal pada Penciptanya, yang berarti pula wayang 
tersebut sudah bebas dari pelanggaran terhadap agama Islam, dan bisa mengantarkan manusia sampai pada Penciptanya.

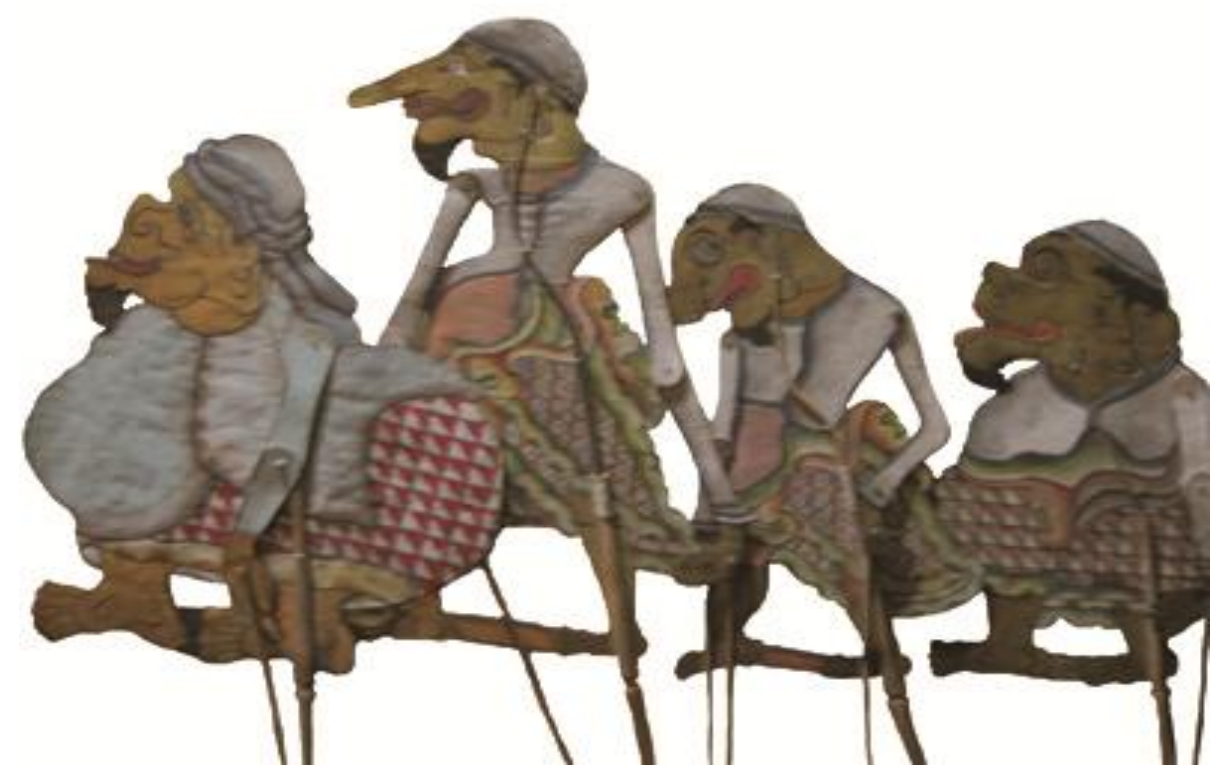

Gambar 2. Wayang Punakawan setelah disambungkan dengan dakwah khuruj fii sabiilillaah, menggunakan pakaian Islami, serban, kupyah, dan gamis, tanpa anting-anting, gelang dan kalung (Gambar Mukti, 2015)

\section{G. Kesimpulan}

Wayang pelanggarannya terhadap agama Islam adalah (1) wayang bukanlah dakwah, (2) bukan taklim, dan (3) bukan ibadah, sehingga wayang tersebut tidak bisa mengantarkan manusia sampai pada Penciptanya. Solusi wayang agar tidak melakukan pelanggaran agama dan bisa mengantarkan manusia sampai pada Penciptanya, wayang harus disambungkan dengan dakwah khuruj fii sabiililaah tiga hari, empat puluh hari, atau empat bulan. 


\section{DAFTAR PUSTAKA}

Abdullah. 2002.Wayang Purwa dan Dakwah. Bandung: Al-Ma'arif.

Hazim, Amir. 1991. Nilai Etis dalam Wayang. Jakarta: Pustaka Sinar Harapan.

Departemen Agama, 1985. Al-Qur'an dan Terjemahannya. Departemen Agama Republik Indonesia Proyek Pengadaan Kitab Suci Al-Qur'an.

Harimawan. 1977. Dramaturgi.Bandung: Remaja Rosdakarya.

Kasidi. 2009. "Estetika Sulukan”. Desertasi untuk memperoleh gelar doktor pada Program studi Ilmu filsafat. Universitas Gajahmada Yogyakarta.

Murtiyoso. 1997. "Faktor-fakrtor Pendukung Popularitas Dalang”. Tesis S-2 Program Studi Pengkajian Seni Pertunjukan Jurusan Ilmu-ilmu Humaniora. Program Pascasarjana Universitas Gajahmada.

Muyosuseno. 2002. Pendidikan budi Pekerti. Surabaya: Jayabaya.

Sahana, Munarsih. 2009. "Show Cats Puppet in a Different Light". Dalam The Jakarta Post, Jum'at 182009.

Soetarno. 1996. Wayang Kulit Jawa. Surakarta. CV. Cinderawasih.

Soetarno. 1978. "Dampak Perubahan Sistem Nilai Terhadap Pertunjukan Wayang Kulit”. Laporan Penelitian, Dibeayai oleh Program DUE Like, No. Kontrak: 343/P/DUE/2000. Sekolah Tinggi IndonesiaSurakarta:96

Sholihin. 2009. "Konferensi Internasional Filsafat Nusantara Program Word Class Reserch University" Fakulktas Filsafat UGM.Seni Budaya Wayang untuk Pengembangan Filsafat Nusantara". Yogyakarta, 2009.

Zakariyya. 2000. Fadlilah Tabligh. Diterjemahkan oleh Abdurrahman. Yogyakarta: Ashshaaff.

Effendi, Zarkasi. 1977. Unsur-unsur Islam dalam Pewayangan. Bandung: Al-Ma’arif.

Van Gronendael. 1985. "Dalang di Balik Wayang". The Rule of The Surakarta dan Yogyakarta. Dardrecht: Forist Publication. 